\title{
Study on Aesthetic Value of Color Art in Movie and TV Animation
}

\author{
Hualong $\operatorname{Ren}^{1, *}$ \\ ${ }^{1}$ Sichuan University, Chengdu, Sichuan 610065, China \\ *Corresponding author. Email: man-made@foxmail.com
}

\begin{abstract}
Color art is the core element of film and television animation. The color not only vividly sets off and reflects the character of the relevant characters in the movie and TV animation, but also exaggerates the overall emotional tone of the movie and TV animation works, vividly expressing and presenting the ideology and value idea of the creator of the animation works. At the same time, the movie animation art has the fictitious and exaggerated characteristics. Therefore, in the choice of color art, using more open colors can effectively convey the public's thoughts and feelings, and emotional collision and resonance. Based on this, the paper comprehensively explores the aesthetic value of color art in film and TV animation from the aspects of transmitting the beauty of picture, rendering the beauty of emotion and creating the beauty of implication.
\end{abstract}

Keywords: Film and television animation, Color art, Aesthetic value, Research.

\section{INTRODUCTION}

In the visual language system of movie and TV animation works, color is the key element, which can not only express the basic artistic atmosphere and tone of movie and TV animation, but also render emotion. It is different from the traditional film and television works, it is more free and open in color rendering performance, and because the characters in the screen is virtual, so the color to bear more functional content.

\section{THE AESTHETIC VALUE OF COLOR ART IN FILM AND TELEVISION ANIMATION}

People's impression of color starts from the things that exist in the objective world, and through the memory of the colors of the objective things, the colors in the memory are applied to the animation works by recollocation and combination, to form a unique personality style of the aesthetic. The aesthetic value of color visual effect, is precisely because of the integration of the subjective feelings, emotions, ideas of the creator, makes the color contrast more obvious, more personal feelings and ideas, but also more resonance to the audience. In the art form of animation, which focuses on design, modeling, language, music, color and script, it is usually necessary to show the charm of the works by many other artistic means, color is not the only means of expression, but it plays an indispensable role in expressing the author's emotion and central idea.

From the history of animation, the development of animation has experienced from black and white two-dimensional silent film era to stereo sound three-dimensional color animation development process. And color plays an important role in the audio-visual art of animation. It serves to shape characters, express emotions, create scenes and render atmosphere in every angle and every shot, make every effort to make the animation works with the role of immersive screen feelings and emotional substitution, from all aspects of the film with the main thrust, to promote the continued development of the plot. The French animated film "The Beautiful City of Crazy Date", with its low contrast dark gray rendering of a busy city, highlights the indifference of the people in the city, and echoes and matches the background of the 1950 s' story, many scenes in the animation are always in low saturation yellow, brown, black tone, there is no strong visual impact, the viewer can focus on the film to express the exaggeration and satire. The use of color in this film can be seen, the 
focus of the film is the expression of the content of ideas, without the use of bright colors to rob the audience of sight.

Each color has its own unique emotional and emotional attributes, people in the long-term practice of social life unconsciously formed an intuitive sense of a certain color, in fact, color itself does not have emotions, however, it can trigger a certain mood or sublimate a certain emotion in many specific situations, making color gradually have emotional attributes. For example, green is often associated with nature, giving people a sense of vitality, youth, fullness, and equality, and is the most tranquil color in nature; red is often associated with blood and fire, can give people inspiration and strength, yellow is associated with paddy fields and the sun, symbolizing harvest and hope, giving a feeling of fullness, comfort, wealth and lucidity; Black is the heaviest color, reminiscent of night and Shadow, usually in a solemn, solemn, terrorist atmosphere, give a person with a sense of gloom, fear, depression. The combination of various colors can not only highlight the creator's creative intention, but also arouse the audience's emotional resonance in color, making the characters in the animated film richer in emotion, at the same time, it makes the emotion that the creator intends to express more clearly perceived by the audience.

\section{THE MULTI-FUNCTION OF COLOR ART IN FILM AND TELEVISION ANIMATION}

Color widely exists and applies in people's daily life, has the very important cognition function. The mixture of color usually has a strong impact on people's vision, but also can give people some hints, cause people's emotional fluctuations and emotional resonance, so color is the most direct and rapid reflection of the human eye perception of the objective world. Because the human eye is very sensitive to color, especially the changing color, when an object comes into the human eye in the way of moving or changing, people usually do not pay attention to the shape of the object itself, and subconsciously focus on the color. Therefore, the animation color in an animated film occupies a pivotal position, and it can more intuitively affect people's perception of the object.

Many advertisers often use color combinations that are sufficiently recognizable on static advertising pages or dynamic advertising videos to attract the attention of potential consumers and create unique color logos for their products, people are more likely to associate this product with the appearance of this iconic color, thus increasing the visibility of the business and consumers' desire to buy goods. In animated movies, color can even become the main symbol for the audience to recognize a character. In animation, color can be used to express the emotions of the characters and describe the atmosphere of the situation. The sad and miserable atmosphere is usually set off by the cold gray and gloomy tone, and the lively and bright scene is usually set off by the fresh tone of green which represents the vitality and blue which represents the vast sky. When describing the emotional changes of the characters, the color collocation should change according to the emotional changes, or the color collocation should change, or the color light and shade should be adjusted, or the color space structure should be reconstructed, these changes can help to portray the role of the character, sublimation of the mood of the character.

As an important and special cultural form, animated film has become an indispensable form of entertainment in modern life. Color, as a symbolic language of expression in animated films, can not only bring strong visual enjoyment to the audience, but also have important ideographic functions. As for the animation film, the thought topic expression plays the function of icing on the cake. The expressive function of color in animated film refers to the relationship between design form and design aim, which is to express the invisible meaning and value through visible external color. In short, the role of color in the animation film cannot be ignored. The expressive function of color in animated film is firstly shown in the symbolic function of color in animated film. The color enriches the psychological suggestion, the audience through own life experience unscrambles in the color to contain but the unclear implication. The symbolic function of color in animated film is that different colors have different symbolic meanings. The use of cool colors such as blue and blue can make people feel depressed, while warm colors such as red and yellow can make people feel excited and nervous. The animation film is to use the combination of cool and warm colors to hint the character's psychology and push the plot forward, and these factors always unconsciously affect our mood. 


\section{THE APPLICATION OF COLOR ART IN FILM AND TELEVISION ANIMATION}

When creating an animated character, color serves only to identify and draw attention to the character, the viewer will have a short memory of the character, and this decorative effect on the character and the scene floats to the surface. A deeper level of characterization should use color features to highlight the character's character characteristics, the audience's impression of the character will not only remember its shape, but also deep inside the character to understand its personality. This is because the emotional characteristics of color can arouse the viewer's emotional experience through visual stimulation, which directly affects the viewer's perception of the character image, it makes it easier for the viewer to perceive the overall character image the designer wants to create more quickly and accurately.

In an animation work, the colors used can reflect the psychological and physiological changes of the characters, express the theme of the animation, the author's feelings, etc. Color, in addition to the role in shaping an important role, but also to a certain extent foils the mood of the characters. Low, dark colors tend to make the viewer feel depressed; bright, vibrant colors make the viewer feel inspired and passionate; fresh, soothing colors make the viewer feel relaxed and relaxed, in this way, different color combinations can make the audience feel the emotions similar to the characters in the play, bringing people into the scene.

Color in the animation film is through the form of constant movement to form a variety of uniform film style. As an important artistic element in animation, color can not only accurately portray the characters' images and characters, but also portray the characters' emotions, create scenes corresponding to the characters' emotions, and enhance the richness of the plot of the picture, help to create and enhance the appreciation of animation film and aesthetic value. In the animation film's lens, each frame color creation and the drawing color creation are similar, has used the color combination and the esthetic. But one of the more difficult aspects of color in film and television animation than in painting is that it not only needs to create static pictures, but also needs to pay attention to the color transformation between pictures, it is a more professional aspect of the animation color art that how to carry on and transform the scene properly. Compared with the painting color, the animation color emphasizes on the dynamic expression of the scene and the plot.

Color in the performance of the emotions and feelings of the characters are deeply affected by the creator, that is, the subjective expression of color. Because animated film and television works want to show their individuality, highlight the main idea and express their feelings, the design of animated color will be more subjective, and the unique nature of animated art, its color collocation is even quite different from the color of real objects, more creative and research-oriented. If only the true thing color copy into the film and television animation, the work will appear more mediocre and popular. Through the color conversion can see that the color not only brings the charm of the audience color itself, but also directly involved in the plot rendering, but also strengthened the theme. Through the design and use of color, the designer can set up the color and the use of color in the scene according to the needs of the story plot and the main role, in order to strengthen and foil and other artistic techniques, to achieve the good, happy, sad, Hope, fear and other circumstances of the atmosphere of rendering and emotional communication.

When creating an animated character, color serves only to identify and draw attention to the character, the viewer will have a short memory of the character, and this decorative effect on the character and the scene floats to the surface. A deeper level of characterization should use color features to highlight the character's character characteristics, the audience's impression of the character will not only remember its shape, but also deep inside the character to understand its personality. This is because the emotional characteristics of color can arouse the viewer's emotional experience through visual stimulation, which directly affects the viewer's perception of the character image, it makes it easier for the viewer to perceive the overall character image the designer wants to create more quickly and accurately.

Color in the animation film is through the form of constant movement to form a variety of uniform film style. As an important artistic element in animation, color can not only accurately portray the characters' images and characters, but also portray the characters' emotions, create scenes corresponding to the characters' emotions, and enhance the richness of the plot of the picture, help to create and enhance the appreciation of animation 
film and aesthetic value. In the animation film's lens, each frame color creation and the drawing color creation are similar, has used the color combination and the esthetic. But one of the more difficult aspects of color in film and television animation than in painting is that it not only needs to create static pictures, but also needs to pay attention to the color transformation between pictures, it is a more professional aspect of the animation color art that how to carry on and transform the scene properly.

The color of the scene in the animation is a relatively static use of color to some extent, because in the same scene, even if the character action is changing, but the relationship between the background color and the character color is basically unchanged. However, with the recommendation of the animation plot, the scene also with the plot ever-changing, these various scenes for the plot has been set in advance. Therefore, the color of different shots in the animation film is always in motion with the passage of time and the advance of the plot.

\section{CONCLUSION}

Color has the function of aesthetic appreciation and expression of emotion, and the use of color in animated films is rich. The creation of color should be closely combined with elements such as the style type, the theme of the story, and the way of expression of the animated films, only when the creator grasps the color structure of the film and conforms to the connotation of the film, can he design the vivid colors in the animated film. At the same time, in the animation film with a rich expression and flavor of subjective color, can strengthen the narrative role of animation film, independent balance of the color screen, sublimation of the film's ideas, interpretation of the film's emotions, so that the animation film art, appreciation of the better promotion.

\section{AUTHORS' CONTRIBUTIONS}

This paper is independently completed by Hualong Ren.

\section{REFERENCES}

[1] Zhu Yuanyuan. Analysis of the aesthetic meaning of color art in film and television animation in the digital age $[\mathrm{J}]$. Popular Literature and Art, 2015, (20).214.
[2] Fu Ye. Analyzing the aesthetic meaning of color art in film and television animation [J]. Film Literature, 2012, (12). 74-75.

[3] Niu Zixing. Exploring the aesthetic meaning of color art in film and television animation [J]. Computer CD Software and Application, 2012, (20),177-178.

[4] Li Song. On the emotional expression of color art in film and television animation [J]. Art Education Research, 2013, (20). 73.

[5] Zhao Jun. The application of artistic subjective color in film and television animation [J]. Film Literature, 2012, (4). 5657.

[6] Zhao Yifan. An aesthetic exploration of color design in the movie La La Land [J]. Henan University of Science \& Technology (Social Science), 2019, (02).63-69.

[7] Jiao Han, Tian Xinghan. The application of color emotion in animation film design-take the animated film "the devil boy of nezha" as an example [J]. Design, 2021, (05) .110-112. 